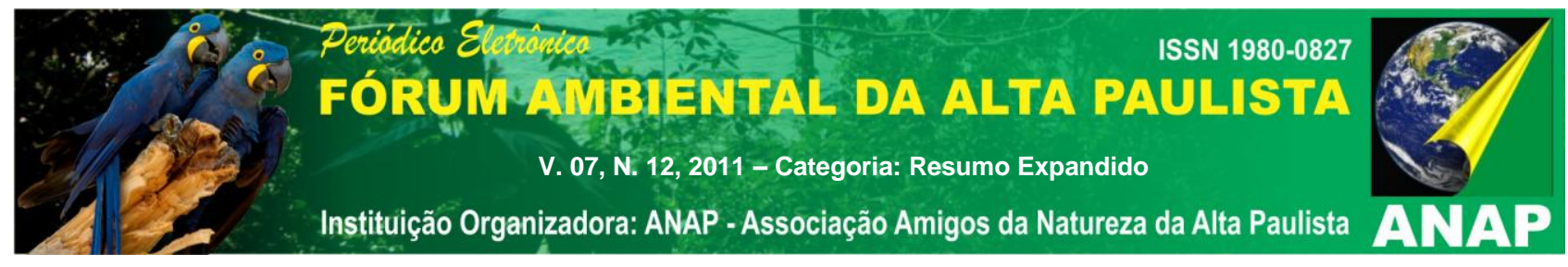

Título do Trabalho

\title{
Análise da eficiência de leitos cultivados no tratamento de efluente suíno
}

Autor principal

Tiago Borges Ferreira

Nomes dos Co autores

Carolina Guimarães Rezende Gobbo; Lilian Tais de Oliveira; Janaína Polyana de Oliveira

Nomes dos Orientadores

Dr. André Luis Fernandes Teixeira

Instituição

Universidade de Uberaba - UNIUBE

E-mail de contato

tiago_bferreira@hotmail; carolinagrgobbo@hotmail.com;

liliantais_oliveira@hotmail.com; janainapolyana@hotmail.com;

andre.fernandes@uniube.br

Palavra chave

Efluente Suíno. Tratamento Secundário. Tremoço Branco.

\section{1- INTRODUÇÃO}

A demanda mundial por proteína animal e o apreço dos consumidores pela carne suína, tem influenciado na criação cada vez mais intensificada destes animais.

Essa forma de produção mais intensificada utiliza um grande volume hídrico, principalmente na limpeza das instalações, produzindo grandes volumes de água de resíduos por unidade animal, que segundo Perdomo (1999) pode passar de 190 l/dia em uma granja de ciclo completo. 


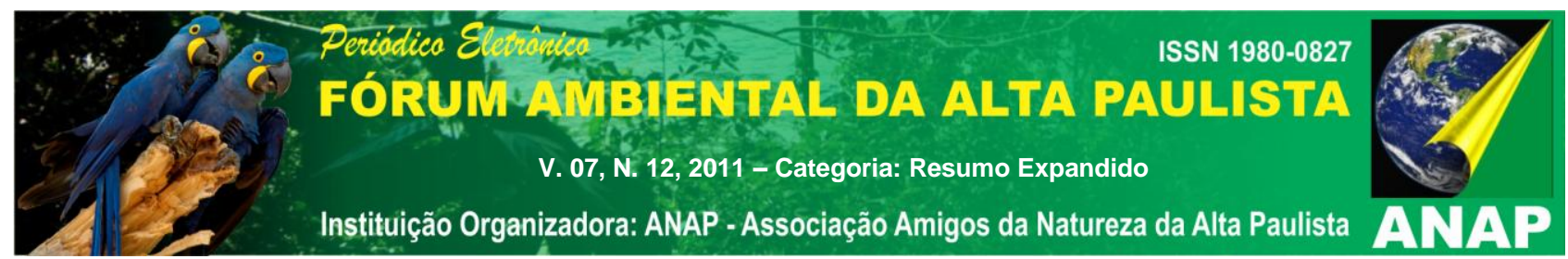

A água residuária suína (ARS) é formada principalmente por dejetos compostos de fezes e urina, restos de ração, pêlos e outros fatores provenientes da produção, os quais formam um efluente muito rico em matéria orgânica e nutrientes.

O efluente suíno se lançado em corpo hídrico é muito prejudicial, chegando a ter uma demanda bioquímica de oxigênio (DBO) 260 vezes maior que o esgoto doméstico. (OLIVEIRA, 2003 apud NOGUEIRA, 2006)

Quando disposto sem critérios em áreas de cultivo de vegetais como nas pastagens, podem desequilibrar mineralmente o solo, elevando alguns nutrientes a níveis tóxicos e/ou limitando o desenvolvimento vegetativo.

Quantidade de ARS maiores que $600 \mathrm{~kg} \cdot \mathrm{ha}^{-1} \cdot \mathrm{ano}^{-1}$ de N representam quantidades tóxicas à ruminantes (WESTERMAN et al.,1987 apud NOGUEIRA, 2006). Essas aplicações diretas, sem tratamento algum, afetam todo o ecossistema envolvido, incluindo solos, ar e água

Nos últimos anos, verificaram-se grandes avanços em pesquisa e desenvolvimento de processos e técnicas de tratamento de águas residuárias, direcionados tanto para sistemas de grande porte e de maior complexidade; quanto de pequeno porte, baixo custo e simplicidade operacional, sendo os leitos cultivados um dos principais sistemas. (MAZZOLA, 2003)

O tratamento de águas residuárias em sistemas alagados construídos (SACs ou leitos cultivados), baseia-se em processos de filtração, de degradação microbiana da matéria orgânica, absorção de nutrientes e adsorção no solo, entre outros (EUSTÁQUIO JUNIOR et al., 2010).

\section{2- OBJETIVO GERAL}

Tendo em vista que, o tratamento de águas residuárias da suinocultura (ARS) em biodigestor anaeróbico não remove toda carga poluente do dejeto impossibilitando o descarte desta em corpos hídricos, o presente trabalho visa avaliar o desempenho de leitos cultivados como alternativa de tratamento secundário, reduzindo a concentração de nutrientes. 


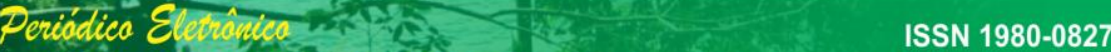 \\ FÓRUM AMBJ̈ ENAL DA ALTA PAULISTA}

V. 07, N. 12, 2011 - Categoria: Resumo Expandido

Instituição Organizadora: ANAP - Associação Amigos da Natureza da Alta Paulista

\section{3- OBJETIVOS ESPECÍFICOS}

Esse trabalho tem como objetivo específico a análise do desempenho de leitos cultivados com 2 (duas) espécies de plantas distintas, sendo elas:

O Tremoço Branco (Lupinus albus L. - IAPAR - 61) e Nabo Forrageiro (Raphanus sativus L. - IPR - 116), com 33 DAP (dias após plantio) e um leito testemunha, sem plantio de vegetais.

Os fatores mais preocupantes deste efluente são as altas concentrações de nutrientes, que foram avaliadas nesse sistema no que diz respeito aos principais parâmetros físico-químicos, Nitrogênio $(\mathrm{N})$, Fósforo $(\mathrm{P})$, Potássio $(\mathrm{K})$, Cálcio $(\mathrm{Ca})$, Magnésio (Mg), Cobre (Cu), Zinco (Zn), Ferro (Fe) e Manganês (Mn)

\section{4- METODOLOGIA}

\subsection{Local do Experimento}

O projeto está sendo desenvolvido em protótipo que se encontra alocado na Universidade de Uberaba - UNIUBE, em Uberaba, Minas Gerais. O clima da cidade é classificado pelo método de Köppen, com Aw, tropical quente e úmido, com inverno frio e seco, com temperatura média de $22,6^{\circ} \mathrm{C}$.

A ARS tratada é coletada na lagoa do biodigestor da Fazenda Escola da Universidade de Uberaba - UNIUBE, na cidade de Uberaba, MG, cujas coordenadas geográficas são: latitude $19^{\circ} 44^{\prime} 13^{\prime \prime} \mathrm{S}$, longitude $47^{\circ} 57^{\prime} 27^{\prime \prime} \mathrm{W}$ e altitude de $850 \mathrm{~m}$. O biodigestor opera em fluxo contínuo e obedece a um modelo implantado pela empresa AgCert em parceria com a Sansuy, IENGEP e Unesp Jaboticabal.

\subsection{Leitos cultivados}

O protótipo atualmente opera com fluxo vertical em batelada, com TDH (tempo de detenção hidráulica) de 24 horas e estão atualmente cultivados com 02 (duas) culturas diferentes. Esse possui 03 (três) caixas, sendo assim, 01 (um) recipiente com cada espécie vegetal, além de uma caixa sem cultivo, para comparações sobre a importância do vegetal no sistema. 


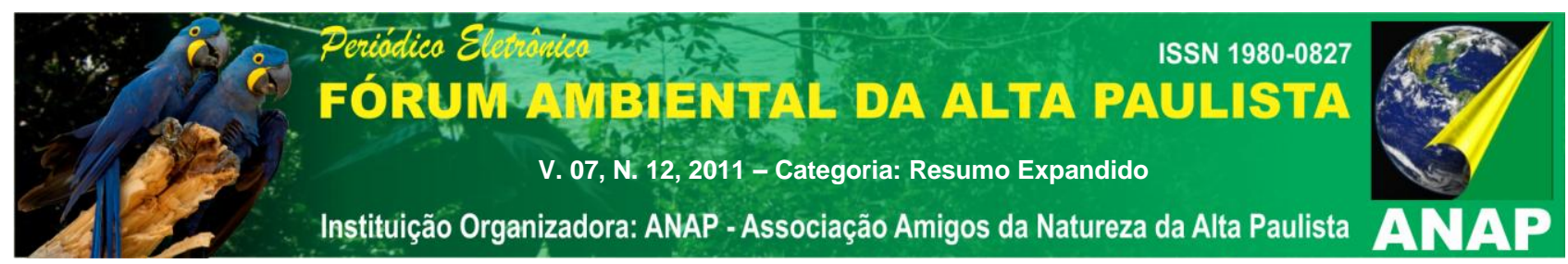

Os leitos são caixas de polietileno com volume máximo de 100 litros, com uma camada inferior formada por $10 \mathrm{~cm}$ de brita $\mathrm{n}^{\circ} 02$ e uma camada superior composta por $20 \mathrm{~cm}$ de areia média.

A entrada e saída de efluentes são feitas por canos de PVC furados com uma espessura de $0,5 \mathrm{~mm}$.

Encontram-se atualmente plantados com as seguintes espécies:

- Tremoço branco (Lupinus albus L.) "IAPAR - 61"

Plantado com 2 (duas) sementes por ponto e espaçamento de aproximadamente $5 \mathrm{~cm}$, o que resulta em uma densidade de $143 \mathrm{gr} / \mathrm{m}^{2}$ ou $1.430 \mathrm{~kg} / \mathrm{ha}$.

- Nabo forregeiro (Raphanus sativus L.) "IPR - 116"

A densidade do plantio foi de $100 \mathrm{gr} / \mathrm{m}^{2}$ ou $1.000 \mathrm{~kg} / \mathrm{ha}$.

O plantio foi realizado no dia 10 de agosto de 2011.

\section{5- RESULTADOS}

\subsection{Das análises - Efluente pré-leito}

Para o efluente antes do leito cultivado, ou seja, apenas tratado no biodigestor, obtivemos; 0,109; 0,076; 0,047; 0,009; 0,002; ALD; ALD; 0,00326; ALD \%, para N, P, K, $\mathrm{Ca}, \mathrm{Mg}, \mathrm{Cu}, \mathrm{Zn}, \mathrm{Fe}$ e $\mathrm{Mn}$ respectivamente. Sendo que a sigla ALD representa valores inferiores a $0,001 \%$.

\subsection{Das análises - Efluente pós-leito}

Para os efluentes após o tratamento no leito cultivado, podemos agrupar segundo o leito:

Leito cultivado com Tremoço branco: 0,182;0,170;0,037;0,046;0,010; ALD; ALD; ALD; ALD \%

Leito cultivado com Nabo forrageiro: 0,157; 0,246; 0,042; 0,030; 0,007; ALD; ALD; ALD; ALD; ALD \%

Leito testemunha: 0,098; 0,101; 0,025; 0,022; 0,004; ALD; ALD; ALD; ALD \%, todos seguindo respectivamente esta ordem, N, P, K, Ca, Mg, Cu, Zn, Fe e Mn. Sendo que a sigla ALD representa valores inferiores a 0,001\% 


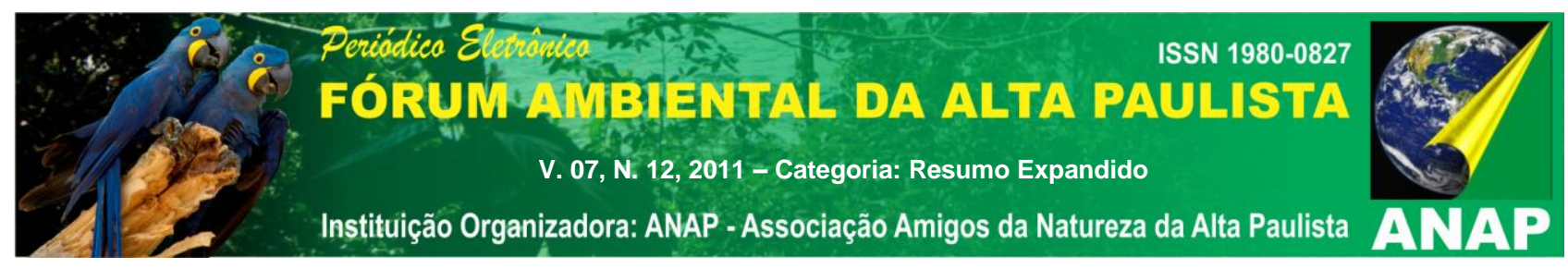

\section{6- CONSIDERAÇÕES FINAIS}

Os leitos cultivados representaram uma alternativa para o tratamento secundário de efluente suíno, no que diz respeito aos parâmetros físico-químicos, segundo a literatura. Porém em especial neste caso, notamos um aumento na concentração de elementos neste efluente.

Por se tratar de um sistema onde foi cultivado espécies vegetais (incluindo o leito testemunha) em uma fase anterior a este experimento, pode estar havendo a decomposição do sistema radicular destas e posterior mineralização dos elementos químicos, possibilitando assim o aumento na concentração destes.

Os resultados não sofreram grandes influências dos vegetais na remoção de nutrientes possivelmente por se encontrarem em uma fase vegetativa um pouco alterada, em decorrência da elevação da temperatura, diminuindo a atividade vegetal, e ataque de lagartas, que diminuíram a área foliar, influenciando na quantidade de luz recebida e consequentemente na redução da fotossíntese, diminuindo a absorção de nutrientes.

Com isso, necessita-se de maior tempo de estudo e maior número de análises para concluirmos sobre a eficiência deste sistema.

\section{7- REFERÊNCIAS}

ESTÁQUIO JUNIOR, V; MATOS, A.T; CAMPOS, L.C; BORGES, A.C. Desempenho agronômico da aveia-preta (Avena strigosa), cultivada em sistemas alagados construídos. Amb-Água, Taubaté, v.5, n.1, p. 68-78, 2010.

FREITAS, W. DA Silva. Desempenho de sistemas alagados construídos com diferentes espécies vegetais, no tratamento de águas residuárias na suinocultura. 2006. 159p. Dissertação (Doutorado em Engenharia Agrícola). Universidade Federal de Viçosa. Viçosa. 2006.

IBGE. Censo Agro 2006: IBGE revela retrato do Brasil agrário. Disponível em <www.ibge.gov.br> acesso em 14 jan. 2011.

MAZZOLA, M. Uso de leitos cultivados de fluxo vertical por batelada no póstratamento de efluente de reator anaeróbio compartimentado. 2003. 98p. Dissertação (Mestrado em Engenharia Agrícola). Universidade Estadual de Campinas. Campinas. 2003 


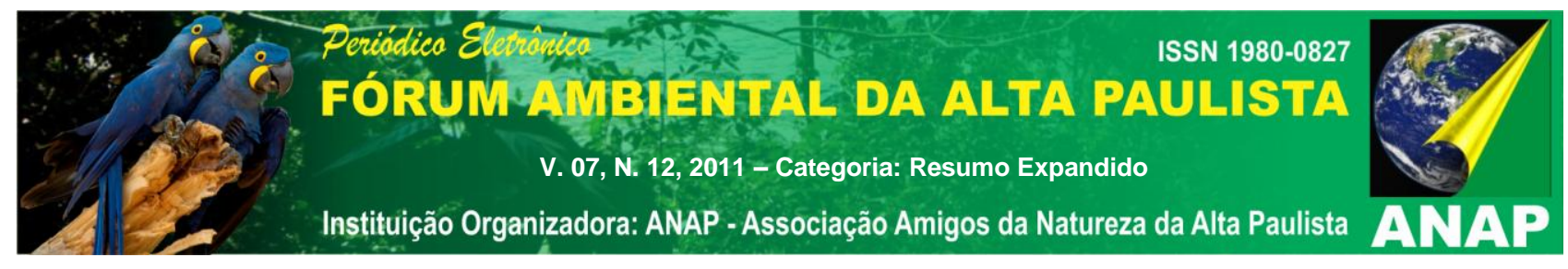

NOGUEIRA, C. C. P; SILVA, I. J. O. Aplicação de Águas Residuárias de Suinocultura na Irrigação. THESIS São Paulo, ano III, v. 6, p. 18-29. 2006. Disponível: <http://www.cantareira.br.>. Acesso em: 14 Jan. 2011.

PERDOMO, C. C.. Sugestões para o manejo, tratamento e utilização de dejetos suínos. Concórdia: Embrapa Suínos e Aves, 1999a. 2p. INSS 1516-554X. Disponível em: <http://www.cnpsa.embrapa.br>. Acesso em: 15 jan. 2011.

SILVA, E. M; DENIS M. ROSTON, D. M. Tratamento de efluentes de sala de ordenha de bovinocultura: Lagoas De Estabilização Seguidas De Leito Cultivado Engenharia Agrícola., Jaboticabal, v.30, n.1, p.67-73, jan./fev. 2010. 